\title{
CAPÍTULO 21: MATURAÇÃO E DEFUMAÇÃO COM FUMAÇA LÍQUIDA EM QUEIJO DE COALHO: ANÁLISE FÍSICO-QUÍMICA E MICROBIOLÓGICA
}

\section{CAPÍTULO 21: MADURACIÓN Y FUMAR CON HUMO LÍQUIDO EN QUESO DE COALHO: ANÁLISIS FÍSICO-QUÍMICO Y MICROBIOLÓGICO}

\author{
CHAPTER 21: MATURATION AND SMOKING WITH LIQUID SMOKE IN \\ COALHO CHEESE: PHYSICAL-CHEMICAL AND MICROBIOLOGICAL \\ ANALYSIS
}

\begin{abstract}
Aurian Moura de Lira ${ }^{1}$; Fernando Moreira Vasconcelos de Oliveira ${ }^{2}$; Gabriel Cicalese Bevilaqua ${ }^{3}$; Neila Mello dos Santos Cortez ${ }^{4}$
\end{abstract}

DOI: https://doi.org/10.31692/978-65-88970-18-8.297-312

\begin{abstract}
RESUMO
O queijo de coalho é um produto típico do Brasil, sendo bastante consumido na região Nordeste, onde é tradicionalmente produzido. Após as etapas de processamento padrão, o queijo de coalho pode ser submetido a uma etapa de maturação, processo no qual ocorre o desenvolvimento de características sensoriais próprias do queijo, como cor, aroma, sabor e textura. Além disso, os queijos de modo geral são alimentos que podem ser submetidos ao processo de defumação, sendo este um método de conservação de alimentos que tem como objetivo, além de preservar o alimento, aprimorar o seu sabor, aroma e textura. Porém, o processo tradicional de defumação pode levar ao produto final compostos cancerígenos oriundos da pirólise da madeira. Nesse contexto, objetivou-se avaliar a viabilidade de produção de um queijo de coalho nas versões maturado e maturado seguido de defumação com fumaça líquida, como uma alternativa ao processo tradicional. Os queijos de coalho foram produzidos e maturados por um período de 10 dias em câmara de maturação com temperatura entre $12^{\circ} \mathrm{C}$ e $14{ }^{\circ} \mathrm{C}$ e umidade relativa do ar entre $85 \%$ e $95 \%$. Após a maturação, parte do queijo maturado foi defumado por imersão em solução aquosa de fumaça líquida por $45 \mathrm{~s}$, secos a temperatura ambiente por $12 \mathrm{~h}$ e armazenados sob refrigeração. Os queijos obtidos foram submetidos a ensaios de $\mathrm{pH}$, acidez, umidade, sólidos totais, cinzas e gorduras e avaliações microbiológicas de estafilococos, Salmonella spp. e coliformes termotolerantes. Os parâmetros físico-químicos avaliados encontraram-se dentro do esperado para o queijo de coalho com exceção do teor de umidade, que ficou abaixo do exigido pela legislação para o queijo de coalho (> 36,0 \%), consequência possivelmente da etapa de maturação. Para as análises microbiológicas realizadas, os resultados obtidos se enquadraram nos limites exigidos pela legislação vigente para padrões microbiológicos em queijos. Percebeu-se, portanto, indicativos de que a aplicação da defumação com fumaça líquida é uma alternativa no desenvolvimento de queijos e pode ser um potencial a ser explorado no queijo de coalho.
\end{abstract}

Palavras-Chave: Defumação, Maturação, Novos produtos, Laticínios.

\section{RESUMEN}

El queso "Coalho" es un producto típico de Brasil, siendo ampliamente consumido en la región Nordeste. Después de las etapas de elaboración estándar, el queso puede someterse a una etapa de maduración, un proceso en el que se desarrollan las características sensoriales, tales como color, aroma, sabor y textura. Además, los quesos en general son alimentos que pueden ser sometidos al proceso de ahumado, siendo este un método de conservación de alimentos que tiene como objetivo, además de conservar el alimento, mejorar su sabor, aroma y textura. Sin embargo, el proceso de ahumado tradicional puede conducir al producto final a compuestos cancerígenos del pirólisis de la madera. En este contexto, este proyecto objetivó evaluar la viabilidad de producir un queso "Coalho" en las

\footnotetext{
${ }^{1}$ Química Industrial, Universidade Federal de Pernambuco, aurianmoura972@gmail.com

${ }^{2}$ Química Industrial, Universidade Federal de Pernambuco, nandomvo@yahoo.com.br

${ }^{3}$ Engenharia de Alimentos, Universidade Federal de Pernambuco, gabriel.cicalese@gmail.com.br

${ }^{4}$ Professora Doutora em Medicina Veterinária, Universidade Federal de Pernambuco, neila.mello@ufpe.br
} 
versiones madurado y madurado seguido de ahumado con humo líquido, como alternativa al proceso tradicional. Los quesos se elaboraron y maduraron por un período de 10 días en una cámara de maduración con temperatura entre $12{ }^{\circ} \mathrm{C}$ y $14{ }^{\circ} \mathrm{C}$ y humedad relativa entre $85 \%$ y $95 \%$. Después de la maduración, parte del queso curado se ahúma por inmersión en una solución acuosa de humo líquido durante $45 \mathrm{~s}$, se seca a temperatura ambiente durante $12 \mathrm{~h}$ y se almacena en refrigeración. Los quesos obtenidos fueron sometidos a pruebas de $\mathrm{pH}$, acidez, humedad, sólidos totales, cenizas y grasas y evaluaciones microbiológicas de estafilococos, Salmonella spp y coliformes termo tolerantes. Los parámetros físico-químicos evaluados estuvieron dentro de lo esperado para el queso, excepto el contenido de humedad, que fue inferior al requerido por la legislación para el queso "Coalho" $>36,0$ $\%$ ), posiblemente como consecuencia de la etapa de maduración. Para los análisis microbiológicos realizados, los resultados obtenidos se situaron dentro de los límites exigidos por la legislación vigente para los estándares microbiológicos en el queso. Por lo tanto, se observaron indicios de que la aplicación del ahumado con humo líquido es una alternativa en la elaboración de quesos y puede ser un potencial a explorar en el queso "Coalho".

Palabras Clave: Ahumado, Maduración, Nuevos productos, Productos lácteos.

\begin{abstract}
"Coalho" cheese is a typical product of Brazil, being widely consumed in the Northeast region, where it is traditionally produced. After the standard processing steps, the "Coalho" cheese can be subjected to a maturation stage, a process in which the sensory characteristics of the cheese, such as color, aroma, flavor and texture, develop. In addition, cheeses in general are foods that can be subjected to the smoking process, this being a method of food preservation that aims, in addition to preserving the food, to improve its flavor, aroma and texture. However, the traditional smoking process can lead to the final product carcinogenic compounds from wood pyrolysis. In this context, this project aimed to evaluate the viability of producing a "Coalho" cheese in the ripened and ripened followed by smoking with liquid smoke versions, as an alternative to the traditional process. The cheeses were produced and matured for a period of 10 days in a maturation chamber with temperature between $12^{\circ} \mathrm{C}$ and $14{ }^{\circ} \mathrm{C}$ and relative humidity between $85 \%$ and $95 \%$. After maturation, part of the cheese was smoked by immersion in an aqueous solution of liquid smoke for $45 \mathrm{~s}$, dried at room temperature for $12 \mathrm{~h}$ and stored under refrigeration. The cheeses obtained were submitted to $\mathrm{pH}$, acidity, moisture, total solids, ashes, proteins and fat tests and microbiological evaluations of staphylococci, Salmonella spp and thermotolerant coliforms. The physico-chemical parameters evaluated were within the expected for "Coalho" cheese, except for the moisture content, which was below that required by the Brazilian legislation for "Coalho" cheese (> 36,0 \%), possibly a consequence of the ripening stage. For the microbiological analyzes carried out, the results obtained fell within the limits required by the current legislation for microbiological standards in cheese. Therefore, it was found that the application of smoking with liquid smoke is an alternative in the development of cheeses and may be a potential to be explored in rennet cheese.
\end{abstract}

Keywords: Dairy products, Maturation, New products, Smoking.

\title{
INTRODUÇÃO
}

O queijo de coalho é um produto típico da região Nordeste, sendo bastante apreciado pela população local devido aos seus aspectos sensoriais característicos como sabor agradável e textura macia. Por ser de fácil produção e ter um bom rendimento, possui um alto valor comercial sendo uma importante fonte de renda para as famílias produtoras (BARROS et al., 2019). De acordo com a IN 30, de 26 de junho de 2001, o queijo de coalho é classificado como um queijo de média a alta umidade, de massa semi-cozida ou cozida e com teor de gordura nos sólidos totais entre 35\% e 60\% (BRASIL, 2001). 
Durante o seu processamento, o queijo de coalho pode passar pela etapa de maturação.

Nessa etapa, o queijo sofre transformações em suas propriedades químicas e físicas que influenciam em sua textura e sabor, gerando produtos que possuem um maior valor agregado no mercado. Os processos ocorridos durante a maturação são influenciados por fatores intrínsecos ao produto, como $\mathrm{pH}$, teor de sal, umidade da massa e microrganismos presentes, e pelas condições do ambiente onde ocorre a maturação, em especial umidade relativa do ar e a temperatura (MCSWEENEY, 2004; OLIVEIRA et al., 2019).

Devido a sua rica composição nutricional, o queijo é um produto bastante vulnerável à proliferação microbiana, podendo inclusive ser contaminado por microrganismos patogênicos que podem causar danos à saúde humana. Nesse sentido, a defumação surgiu historicamente como um método de conservação em que os alimentos são expostos a fumaça proveniente diretamente da madeira ou na sua forma líquida. Além de conservar o alimento, a defumação tem como objetivo aprimorar seus aspectos sensoriais (COSTA et al., 2008; PEDRAL et al., 2015; COUTINHO et al., 2020).

A depender do tipo de produto alimentício, podem ser utilizadas diferentes técnicas de defumação, sendo a quente ou a frio duas classificações tradicionais possíveis para o processo. $\mathrm{Na}$ defumação a quente o alimento é exposto diretamente a fumaça proveniente da madeira, enquanto que na defumação a frio a fumaça é produzida fora da câmara de defumação, de forma que a temperatura não ultrapasse os $30^{\circ} \mathrm{C}$. Durante o processo de defumação há modificações nas características sensoriais dos alimentos, como odor, sabor, coloração e textura, o que pode tornar o produto mais atraente para o consumidor (PEDRAL et al., 2015).

A defumação tradicional pode ser substituída pelo uso da fumaça líquida, que é obtida pela combustão de materiais que contêm celulose, hemicelulose e lignina. Cascas de café, bambu e palha de arroz são exemplos de materiais que podem ser utilizados para a obtenção da fumaça líquida. $\mathrm{O}$ uso da fumaça liquida apresenta vantagens como higiene, menor tempo de processamento, diminuição da poluição ambiental e variedade na utilização da fumaça (COSTA et al., 2008; ALI et al., 2021).

Considerando o contexto apresentado, e sabendo da necessidade constante de desenvolvimento de novos produtos e processos para o mercado, objetivou-se avaliar o potencial de obtenção de um queijo de coalho maturado e defumado empregando fumaça líquida como alternativa ao processo tradicional de defumação. 


\section{Queijo de Coalho}

O queijo de coalho é um produto tipicamente brasileiro, sendo produzido na região Nordeste há mais de 150 anos a partir do leite cru ou pasteurizado. Os principais estados nordestinos produtores de queijo de coalho são: Pernambuco, Ceará, Rio Grande do Norte e Paraíba (LIMA et al., 2017).

O queijo de coalho tem como principais características o sabor levemente ácido e salgado e resistência ao aquecimento sem derreter, o que possibilita que seja preparado frito ou assado, além de ser utilizado em diversas preparações culinárias. O processo produtivo do queijo de coalho é simples e não exige equipamentos sofisticados, de forma que a produção desse queijo é realizada principalmente por pequenas e médias queijarias de agricultura de base familiar e propriedades rurais de pequeno porte (LIMA et al., 2017; BARROS et al., 2019; OLIVEIRA et al., 2020).

Segundo a IN $\mathrm{N}^{\circ}$ 30, do MAPA (BRASIL, 2001) o queijo de coalho é definido como “o queijo que se obtém por coagulação do leite por meio do coalho ou outras enzimas coagulantes apropriadas, complementada ou não pela ação de bactérias lácteas selecionadas e comercializado normalmente com até 10 (dez) dias de fabricação". De acordo com a IN citada, o queijo de coalho é classificado como um queijo de média a alta umidade, de massa semicozida ou cozida e que possui teor de gordura nos sólidos totais variando entre $35 \%$ e $60 \%$. Os ingredientes obrigatórios na produção do queijo de coalho são o leite integral ou padronizado a $3 \%$ de gordura e coalho ou outras enzimas coagulantes apropriadas, podendo ou não ter a adição de outros ingredientes, como cultivo de bactérias láticas, cloreto de sódio, condimentos e especiarias.

O queijo de coalho deve apresentar as seguintes características sensoriais: consistência semidura e elástica, textura compacta e macia, cor branco amarelado uniforme, sabor brando e ligeiramente ácido e odor ligeiramente ácido, pode apresentar algumas olhaduras pequenas ou não ter olhaduras (BRASIL, 2001). De acordo com Nassu, Macedo e Lima (2006), a produção do queijo de coalho envolve as seguintes etapas: recepção do leite, pasteurização, adição do fermento, cloreto de cálcio e coalho, corte da coalhada, mexedura, cozimento da massa, salga, enformagem, prensagem, viragem, maturação, embalagem e armazenamento. A Maturação é uma etapa opcional na produção de queijo de coalho e é realizada em câmara refrigerada, à temperatura de $10{ }^{\circ} \mathrm{C}$ a $12{ }^{\circ} \mathrm{C}$, durante 5 a 10 dias. 
Uma das últimas etapas da produção dos queijos, a maturação é um processo no qual ocorre uma série de transformações de ordem biológica, química e bioquímica pela ação de enzimas lipolíticas e proteolíticas no queijo. A maturação é realizada em câmaras com controle de temperatura e umidade, e é responsável por alterações nas propriedades químicas e físicas e pelo desenvolvimento do sabor, textura e aparência do queijo (COSTA JUNIOR et al., 2014; VIDAL; NETTO, 2018).

A maturação do queijo é catalisada pela atividade metabólica dos organismos vivos e enzimas provenientes desses organismos e de outras fontes, como do próprio leite utilizado no processo e do coagulante. O processo bioquímico de maturação do queijo é constituído por três vias principais, sendo elas: metabolismo da lactose residual, do lactato e do citrato, proteólise e catabolismo de aminoácidos, lipólise e metabolismo de ácidos graxos. O tempo de maturação depende do tipo de queijo produzido, podendo durar semanas ou até mesmo anos (MCSWEENEY, 2004; VIDAL; NETTO, 2018; COSTA JUNIOR et al., 2014).

Aproximadamente $96 \%$ da lactose do leite é perdida no soro, porém a coalhada ainda possui quantidade significativa de lactose que durante a maturação é fermentada pelas bactérias láticas, com produção de ácido lático que posteriormente é convertido em lactato. O lactato, por sua vez, é metabolizado por bactérias que produzem propionato e acetato, compostos que contribuem com o sabor e aroma do queijo. Outras bactérias metabolizam o citrato, gerando outros compostos aromáticos como diacetil e acetaldeído (CRUZ et al., 2017; NERO; CRUZ; BERSOT, 2017).

Além da lactose, as proteínas e os lipídios também podem ser metabolizados durante a maturação, atuando como substratos de proteólises e lipólises, gerando compostos como aminoácidos, álcoois, cetonas e éteres, que contribuem no sabor e no aroma dos queijos (CRUZ et al., 2017; NERO; CRUZ; BERSOT, 2017).

\section{Defumação}

A defumação é um dos processos tecnológicos de alimentos mais antigos, e vem sendo utilizado como método de preservação dos alimentos há muito tempo na história da humanidade. Alimentos defumados desempenharam um importante papel na alimentação da população europeia durante as guerras mundiais, quando o abastecimento de alimentos foi prejudicado, sendo esse o provável motivo pelo qual alguns alimentos defumados são mais 
populares na Europa do que nas Américas. O uso da refrigeração para conservar alimentos a

partir dos anos 1900 diminuiu a aplicação da defumação como método de conservação, no entanto, ainda existe uma significativa demanda dos consumidores pelos alimentos defumados, devido às suas características organolépticas (JAFFE; WANG; CHAMBER IV, 2017; LEDESMA; RENDUELAS; DIAZ, 2017).

Os principais grupos de alimentos defumados incluem carnes, pescados, bebidas e especiarias. A popularidade do mercado de alimentos defumados tem aumentado, incluindo o mercado de queijos defumados, que cresceu como uma categoria especializada de queijos aromatizados. Tradicionalmente, a defumação do queijo costumava ser utilizada para aumentar seu tempo de vida útil. Atualmente, no entanto, costuma ser aplicada ao queijo para obtenção de um produto diferenciado. No queijo de coalho, especificamente, a defumação promove ação antioxidante e antimicrobiana e sabor diferenciado pela ação dos componentes da fumaça (LEDESMA; RENDUELA; DIAZ, 2017; BENEVIDES et al., 2018: DEL TORO-GIPSON et al., 2021).

A fumaça, seja proveniente da queima direta da madeira ou na forma líquida, possui diversas substâncias, como fenóis, álcoois, ácidos orgânicos, carboidratos e hidrocarbonetos. As substâncias fenólicas formadas são impregnadas no produto e reduzem a rancidez lipídica dos alimentos, promovendo efeito preservativo. No processo de defumação também acontece a modificação de características sensoriais dos alimentos, como odor, sabor, cor e textura, sendo o aroma um dos aspectos mais marcantes. Dessa forma, o alimento defumado possui sabor, aroma, cor e textura típicos (PEDRAL et al., 2015; BENEVIDES et al., 2018).

As técnicas a serem utilizadas no processo de defumação dependem de fatores como o produtos a ser defumado, a temperatura aplicada, o tempo de defumação, o tipo de processo e a madeira empregados. Nos métodos de defumação direta, a fumaça é produzida na mesma câmara onde o alimento é processado. Os principais métodos de defumação direta empregam as técnicas tradicionais de defumação, como a defumação a quente e a frio, que variam de acordo com a temperatura da câmara de defumação (PEDRAL et al., 2015; LEDESMA; RENDUELAS; DIAZ, 2017; BENEVIDES et al., 2018).

O processo de defumação líquida é um dos métodos de defumação mais rápidos, consistindo geralmente na imersão do alimento em solução aquosa de extratos líquidos da fumaça, conhecida comercialmente como fumaça líquida. A defumação líquida pode ser aplicada em uma grande variedade de alimentos, como carnes, pescados e queijos, inclusive podendo ser aplicada em alimentos que não são tradicionalmente defumados (DUARTE; VIEIRA; GHERARDI, 2017; RIBEIRO et al., 2018). 
A fumaça líquida é obtida pela queima de materiais ricos em celulose, hemicelulose e

lignina. Sua composição é influenciada por fatores, como o tipo de madeira utilizada e temperatura de combustão da madeira e afeta o $\mathrm{pH}$, o sabor e a durabilidade do armazenamento do produto. É possível encontrar compostos de diversos grupos na fumaça líquida, como álcoois, ácidos, carbonilas e fenóis, sendo estes últimos os principais responsáveis pelo sabor (ALI et al., 2021).

Todo processamento de alimentos com tratamento térmico a altas temperaturas ou contato direto com gases de combustão pode desencadear a formação de altos níveis de hidrocarbonetos policíclicos aromáticos (HPAs) nos alimentos. Os hidrocarbonetos policíclicos aromáticos são compostos orgânicos formados por carbono e hidrogênio e que possuem dois ou mais anéis aromáticos condensados em sua estrutura. São gerados pela combustão incompleta ou pirólise de matéria orgânica, sendo reconhecidos por sua toxicidade e pelo seu potencial carcinogênico para animais e para o ser humano (MOZANER; ALMEIDA; SILVA, 2019).

Como nos métodos tradicionais de defumação a fumaça entra em contato direto com o alimento, pode haver a formação desses compostos caso não haja um bom controle do processo. No caso dos queijos, há um risco de contaminação maior por se tratar de um alimento com alto teor de lipídios, pois os HPAs possuem natureza lipofílica (GUILLÉN et al., 2011; AYDINOL; OZCAN, 2013).

Por se tratar de um método de defumação indireta, onde o alimento não entra em contato direto com a fumaça produzida pela queima da madeira, a defumação líquida pode reduzir significativamente a quantidade de HPAs nos alimentos defumados, além de apresentar outras vantagens, como menor poluição ambiental, maior uniformidade na cor e sabor e alta deposição de substâncias oxidantes. Pelos motivos citados, a defumação líquida tem substituído cada vez mais a defumação tradicional (DUARTE; VIEIRA; GHERARDI, 2017; LEDESMA; RENDUELAS; DIAZ, 2017; RIBEIRO et al., 2018).

\section{METODOLOGIA}

\section{Obtenção do leite}

O leite utilizado foi coletado no sítio Bananeiras, localizado no município de Ibateguara - AL e mantido em refrigeração durante todo o transporte até a chegada ao Laboratório de Produtos de Origem Animal (Leites) da Universidade Federal de Pernambuco (UFPE), onde 
foi pasteurizado e utilizado para a produção dos queijos.

\section{Produção dos queijos}

O processo de produção do queijo de coalho seguiu a metodologia de Furtado (2005). Após o aquecimento do leite pasteurizado a $35^{\circ} \mathrm{C}$, adicionou-se primeiramente cloreto de cálcio e, posteriormente, a enzima coagulante, ambos da marca Rica Nata®, diluídos em um pequeno volume de água destilada e seguindo as recomendações dos fabricantes quanto ao volume utilizado de cada produto. O processo seguiu nas etapas de coagulação, corte, mexedura, aquecimento e prensagem.

\section{Maturação dos queijos}

Os queijos obtidos foram maturados em câmara de maturação por 10 dias com temperatura de $12{ }^{\circ} \mathrm{C}$ a $14{ }^{\circ} \mathrm{C}$ e umidade relativa do ar de $85 \%$ a $95 \%$, com os queijos sendo virados diariamente para garantir a uniformização do aspecto do produto após a maturação e com pesagem diária para o acompanhamento da umidade do produto. Após o período de maturação, os queijos foram embalados em sacos plásticos próprios para alimentos e mantidos sob refrigeração $\left(6 \pm 2{ }^{\circ} \mathrm{C}\right)$.

\section{Defumação líquida do queijo de coalho}

Parte dos queijos de coalho produzidos e maturados foi submetida ao processo de defumação líquida. Para isso, o queijo foi inserido por $45 \pm 1$ segundos em uma solução aquosa de fumaça líquida Docina Nutrição ${ }^{\circledR}$ na proporção de $30 \%$, seguido de secagem à temperatura ambiente por $12 \pm 1 \mathrm{~h}$. Os queijos maturados e defumados produzidos foram embalados em sacos plásticos próprios para alimentos e mantidos sob refrigeração $\left(6 \pm 2{ }^{\circ} \mathrm{C}\right)$.

\section{Análises físico-químicas dos queijos}

Com os queijos produzidos e maturados ou maturados e defumados, foram realizadas análises físico-químicas seguindo os procedimentos descritos na IN de nº6 de 2006 do MAPA (BRASIL, 2006). Foram determinadas a acidez, por titulação com acidímetro de Dornic, o pH, com o equipamento de bancada (pHmetro BEL PHS3-BW), o teor de gorduras, pelo método 
butirométrico, e o de umidade e cinzas, pelo método gravimétrico. Ressalta-se que o teor de

sólidos totais é determinado a partir da subtração do teor de umidade do valor unitário (100\%) e o teor de Gordura no Extrato Seco (GES) pode ser determinado a partir da relação entre o percentual de gordura e o percentual de sólidos totais.

\section{Análises Microbiológicas}

A análise de coliformes termotolerantes foi feita pela técnica do Número Mais Provável (NMP) de Merck (2002) adaptada por Franco e Leite (2005). Foram feitas diluições de $10^{-1}$ a $10^{-3} \mathrm{~g} / \mathrm{mL}$ das amostras de queijos com solução salina peptonada $0,1 \%$ como diluente. De cada diluição foi transferido $0,1 \mathrm{~mL}$ para tubos Eppendorf contendo $1 \mathrm{~mL}$ de caldo Fluorocult, sendo utilizados três tubos para cada diluição. Em seguida, os tubos foram incubados a $36{ }^{\circ} \mathrm{C} \pm 1{ }^{\circ} \mathrm{C}$ por $24 \mathrm{~h}$. Os tubos que apresentaram coloração azul e/ou esverdeada foram colocados em contato com luz ultravioleta (UV - 350nm), onde a fluorescência dos tubos seria indicativo para a presença de coliformes termotolerantes.

A determinação do Número Mais Provável foi realizada com a tabela de Hoskins para três tubos. A análise foi realizada nos dois queijos obtidos, uma vez por semana, por duas semanas consecutivas.

Para a contagem de Staphylococcus aureus, foi realizado o espalhamento de $0,1 \mathrm{~mL}$ das diluições descritas anteriormente em placas de Petri contendo meio Ágar Baird-Parker (BP), emulsão de gema de ovo e telurito de potássio 0,01\%. As placas contendo as amostras foram incubadas a $36^{\circ} \mathrm{C} \pm 1{ }^{\circ} \mathrm{C}$ por $48 \mathrm{~h}$. Os resultados foram avaliados pela contagem de colônias negras típicas de Staphylococcus spp. e observação de possíveis colônias negras brilhantes com halos translúcidos ao redor, indicativo de Staphylococcus aureus (APHA, 2015).

A pesquisa de Salmonella spp. foi feita em três etapas. No pré-enriquecimento, foi realizada uma diluição de $10^{-1} \mathrm{~g} / \mathrm{mL}$ nas amostras com solução salina peptonada $1 \%$ tamponada como diluente, em seguida, as amostras foram incubadas a $36^{\circ} \mathrm{C}$ por $20 \mathrm{~h}$. No enriquecimento seletivo foi transferido $0,1 \mathrm{ml}$ da amostra para tubos com caldo Rappaport Vassiliadis e $1 \mathrm{ml}$ da amostra para tubos com caldo selenito sistina. Os tubos foram incubados a $41^{\circ} \mathrm{C} \pm 1^{\circ} \mathrm{C}$ por $24 h$.

Em seguida, foi feita a inoculação por esgotamento de cada um dos enriquecimentos nos caldos Rappaport Vassiliadis e Selenito Cistina em duas placas de Petri, sendo uma com o meio Ágar Xilose Lisina Desoxicolato (XLD) e outra com o meio Ágar Rambach, sendo ambos meios sólidos. Após o período de incubação, foi verificado se houve crescimento de colônias 
típicas de Salmonella no meio (APHA, 2015).

\section{RESULTADOS E DISCUSSÃO}

\section{Análises Físico-Químicas}

Os resultados obtidos para as análises físico-químicas realizadas nos queijos produzidos encontram-se na Tabela 01.

Tabela 01: Valores médios e desvio padrão das análises físico-química dos queijos de coalho maturado (QM) e maturado seguido de defumação (QMD)

\begin{tabular}{ccc}
\hline Característica & QM & QMD \\
pH & $6,67 \pm 0,01^{\mathrm{a}}$ & $6,69 \pm 0,01^{\mathrm{a}}$ \\
Acidez (\% de ácido lático) & $0,12 \pm 0,01^{\mathrm{a}}$ & $0,12 \pm 0,00^{\mathrm{a}}$ \\
Sólidos Totais (\%) & $75,78 \pm 5,29^{\mathrm{a}}$ & $76,19 \pm 7,80^{\mathrm{a}}$ \\
Umidade (\%) & $24,22 \pm 5,29^{\mathrm{a}}$ & $23,81 \pm 7,80^{\mathrm{a}}$ \\
Cinzas (\%) & $8,16 \pm 0,61^{\mathrm{a}}$ & $7,18 \pm 0,72^{\mathrm{a}}$ \\
Gordura (\%) & $27,50 \pm 0,70^{\mathrm{a}}$ & $27,50 \pm 1,40^{\mathrm{a}}$ \\
Gordura no Extrato Seco - GES (\%) & $36,30 \pm 1,60^{\mathrm{a}}$ & $36,40 \pm 5,50^{\mathrm{a}}$ \\
\hline Nota: Letras diferentes numa mesma linha indicam diferença estatisticamente significativa pelo teste de \\
Tukey ao nível de significância de 5\%.
\end{tabular}

De acordo com Pinto et al. (2016), pH abaixo de 4,6 reduz a possibilidade de crescimento de micro-organismos potencialmente patógenos nos alimentos, sendo que o $\mathrm{pH}$ próximo a neutralidade obtido para os queijos ressalta a importância do rigor no processamento do produto para evitar sua contaminação. O valor do $\mathrm{pH}$ se relaciona com a textura dos queijos, de modo que queijos com $\mathrm{pH}$ mais alto costumam apresentar textura mais firme, enquanto queijos com pH mais baixo geralmente possuem textura mais mole (FERREIRA NETO et al., 2017). Tal relação foi observada nos queijos produzidos, pois ambos apresentaram textura firme.

Os resultados obtidos para $\mathrm{pH}$ dos queijos produzidos não foram equivalentes aos obtidos por Machado et al. (2011), que produziram diferentes queijos de coalho com adição de fermento e ácido lático estabilizados por 3 a 5 dias com temperatura entre 12 e $14{ }^{\circ} \mathrm{C}$ e umidade igual a $85 \%$, obtendo valores de $\mathrm{pH}$ entre 6,19 e 6,26. Essa diferença é reflexo do uso do fermento e do ácido lático, que reduzem o $\mathrm{pH}$ do produto final, logo, os queijos QM e QMD, em que não houve a adição destes, o pH aproximou-se mais da neutralidade.

Os resultados de $\mathrm{pH}$ coincidem com o de Ferreira Neto et al. (2017), que produziu queijo de coalho maturado e defumado com orégano e erva doce aplicando diferentes tempos de 
defumação e obteve valores de pH entre 6,0 e 6,7 para os queijos produzidos.

Em relação a acidez, segundo Sousa et al. (2014), a acidez proveniente da produção de ácido láctico pela fermentação da lactose influencia diretamente na fase inicial da maturação. Os resultados obtidos para a acidez titulável dos queijos produzidos neste trabalho foram iguais 0,12\% de ácido lático para ambos os queijos e coincidiram com os obtidos pelo referido autor, que encontrou valores de acidez entre $0,12 \%$ e 1,01\%. Apesar disso, ressalta-se que a acidez após a maturação poderia ter sido maior caso fosse adicionado uma cultura fermentativa durante o processamento do queijo, pois a mesma poderia promover uma maior produção de ácido lático.

Quanto aos valores determinados para os teor de umidade, os queijos QM e QMD se enquadraram na classificação de queijos de baixa umidade, ou seja, com umidade inferior a 35,9\% (BRASIL, 1996). O valor da umidade encontra-se fora dos padrões exigidos pelo regulamento técnico de identidade e qualidade de queijo de coalho, que o classifica como um queijo de média a alta umidade, apesar disso, ressalta-se que essa legislação se limita ao queijo de coalho fresco, não abordando o maturado e/ou defumado (BRASIL, 2001). Nesse sentido, era esperado que ocorresse uma perda de água devido aos processos de maturação e defumação, porém, tal efeito pode ser reduzido a partir do maior controle da temperatura e umidade da câmara durante o período de maturação.

Em relação ao teor de GES, os queijos QM e QMD puderam ser enquadrados na classificação de queijos semigordos, ou seja, com o teor de GES entre 25,0\% e 44,9\% (BRASIL, 1996). De acordo com o regulamento técnico de identidade e qualidade de queijo de coalho, o teor de gordura nos sólidos totais do queijo de coalho deve ser variável entre 35,0\% e 60,0\% (BRASIL, 2001). Dessa forma, os queijos produzidos se enquadraram nos padrões exigidos pela legislação em tal parâmetro.

\section{Análises Microbiológicas}

A partir da colimetria realizada, verificou-se que em ambos os queijos encontrava-se uma quantidade de coliformes termotolerantes inferior a $3 \mathrm{NMP} / \mathrm{mL}$, que é o limite de detecção do método. Como inferiu-se a ausência de coliformes termotolerantes, grupo que engloba $E$. coli, não foi necessário realizar o teste de detecção de tal bactéria e, portanto, os produtos encontraram-se de acordo com a legislação, que define uma concentração máxima de $5 \times 10^{2}$ UFC/g de E. coli. (BRASIL, 2019). Ressalta-se que é comum encontrar na literatura pesquisas onde foram analisados queijos de coalho com alta contagem de coliformes termotolerantes. 
Bezerra et al. (2017), por exemplo, realizou uma avaliação microbiológia do queijo de coalho comercializado no estado da Paraíba, encontrando coliformes termotolerantes em concentrações acima de $5 \times 10^{2} \mathrm{UFC} / \mathrm{g}$ em 74,4\% das amostras analisadas.

Em relação à contagem de estafilococos totais, foram obtidos valores na ordem de $10^{4}$ UFC/g para o QM e $10^{5} \mathrm{UFC/g}$ para o QMD. Por os estafilococos serem bactérias presentes inclusive na pele humana, sua presença nos queijos é justificada pela própria manipulação durante o procssamento. Apesar disso, não foi constatada nenhuma colônia como estafilococo coagulase positiva, o que seria um indicativo da presença de Staphylococcus aureus, bactéria capaz de produzir enterotoxinas nos alimentos. Dessa forma, os queijos produzidos estavam de acordo com o padrão microbiológico definido pela legislação, que define um limite máximo de $10^{3} \mathrm{UFC} / \mathrm{g}$ de estafilococos coagulase positiva (BRASIL, 2019).

Por fim, em relação à pesquisa de Salmonella spp, não foram identificadas colônias típicas do microrganismo nos meios avaliados. Ressalta-se que Salmonella é um importante agente patógeno capaz de provocar infecções alimentares, por isso a legislação determina que seja determinada a ausência de tal microrganismo nos produtos (BRASIL, 2019).

Desse modo, percebeu-se, portanto, que os queijos QM e QMD encontraram-se dentro do padrão esperado pela legislação brasileira, possibilitando a classificação dos mesmos como microbiológicamente seguros para o consumo humano em relação aos microrganismos avaliados.

\section{CONCLUSÕES}

Percebeu-se que foi possível obter queijos de coalho maturados e maturados seguidos de defumação com fumaça líquida seguros em relação aos parâmetros microbiológicos testados. Tais produtos obtiveram teores de gordura no extrato seco de acordo com os limites exigidos pela legislação vigente. Apenas os valores obtidos para a umidade dos queijos não atenderam aos valores estabelecidos na legislação de queijo de coalho, mas é possível garantir um maior controle deste parâmetro pelo ajuste da temperatura e umidade da câmara na etapa de maturação. Dessa forma, com o controle adequado, as etapas de maturação e defumação líquida são viáveis na produção do queijo de coalho, podendo acrescentar características diferenciadas ao queijo. 
ALI, F.; CUNDARI, L.; MISKAH, S.; PRASETYO, H. Effect of Variations Concentration and $\mathrm{pH}$ of Liquid Smoke in the Immersion With Various Types of Fish. Atlantis Highlights in Engeneering, v. 7, 2021.

APHA - American Public Health Association. Compendium of Methods for the Microbiological Examination of Foods. 5th ed. [S. l.]: APHA Press, 2015

AYDINOL, P.; OZCAN, T. The effect of natural and liquid smokes on the benzo[a] pyrene content and quality parameters of Circassian cheese. International Journal Of Dairy Technology, abr., 2013.

BARROS, D. de M.; MACHADO, E. de C. L.; MOURA, D. F. de; FONTE, R. A. B. da; FERREIRA, S. A. de O.; BEZERRA, R. de S.. Aspectos do queijo de coalho com ênfase na importância das Boas Práticas de Fabricação no sistema de produção. Brazilian Journal Of Development, Curitiba, v. 5, n. 1, p. 67-93, jan. 2019.

BENEVIDES, S. D.; EGITO, A. S. do; LAGUNA, L. E.; SANTOS, K. M. O. dos; GARRUTI, D. dos S.; DELIZA, R.; ARAÚJO, Í. M. da S.; QUEIROGA, R. de C. R. do E.. Validação e Transferência da Tecnologia de Queijo Coalho Caprino Maturado e Defumado. Fortaleza, CE: Embrapa Agroindústria Tropical, 2018.

BEZERRA, D. E. L.; SILVA FILHO, C. R. M. da; GOMES, D. J.; PEREIRA JUNIOR, E. B. Avaliação microbiológica de queijo de coalho comercializado na feira livre de Sousa - Paraíba. Revista Principia - Divulgação Científica e Tecnológica do IFPB, v. 1, n. 37, p. 85-91, Instituto Federal de Educacao, Ciencia e Tecnologia da Paraib, 2017.

BRASIL. Instrução Normativa $N^{\circ} 30$ de 26 de Junho de 2001. Aprova o Regulamento Técnico de Identidade e Qualidade de Manteiga da Terra ou de Garrafa; Queijo de Coalho e Queijo de Manteiga. Ministério da Agricultura, Pecuária e Abastecimento, Brasília, DF, 2001.

BRASIL. Instrução Normativa $\mathrm{N}^{\circ} 68$ de 12 de Dezembro de 2006. Oficializa os Métodos Analíticos Oficiais Físico-Químicos, para Controle de Leites e Produtos Lácteos, Ministério da Agricultura, Pecuária e Abastecimento, Brasília, DF, 2006.

BRASIL. Instrução Normativa $\mathrm{N}^{\circ}$ 60, de 23 de dezembro de 2019.. Estabelece as Listas de Padrões Microbiológicos Para Alimentos. Diário Oficial da União, 26 dez. 2019.

BRASIL. Portaria $\mathrm{N}^{\circ} 146$ de 07 de março de 1996. Aprova os regulamentos técnicos de identidade e qualidades dos produtos lácteos, Ministério da Agricultura, Pecuária e Abastecimento, Brasília, DF, 1996.

COSTA JÚNIOR, L. C. G.; MORENO, V. J.; MAGALHÃES, F. A. R.; COSTA, R. G. B.; RESENDE, E. C.; CARVALHO, K. B. A. Maturação do queijo minas artesanal da microrregião campo das vertentes e os efeitos dos períodos seco e chuvoso. Revista do Instituto de Laticínios Cândido Tostes, Juiz de Fora, v. 69, n. 2, p. 111-120, 6 maio 2014

COSTA, A. P. R.; ANDRADE, D. R. de; VIDAL JÚNIOR, M. V.; CORDEIRO, C. A. M.; 
SOUZA, G.; ERTHAL JUNIOR, M.; SOUZA, C. L. M. de. Defumação de filés de piauvermelho (Leporinus copelandi) com o uso de fumaça líquida. Revista Ceres, [S.I.], v. 55, n. 4, p. 251-257, 2008.

COUTINHO, M. G. S.; NEVES, A. M.; BATISTA, A. S. M.; FONTENELlE, R. O. dos S. Utilização de óleos essenciais na conservação de queijo: revisão. Revista do Instituto de Laticínios Cândido Tostes, Juiz de Fora, v. 75, n. 2, p. 126-141, jun. 2020.

CRUZ, A. G.; ZACARCHENCO, P. B.; OLIVEIRA, C. A. F.; CORASSIN, Carlos H. Processamento de Produtos Lácteos: queijos, leites fermentados, bebidas lácteas, sorvete, manteiga, creme de leite, doce de leite, soro em pó e lácteos funcionais. Rio de Janeiro: Elsevier, 357 p., 2017.

DEL TORO-GIPSON, R.S.; RIZZO, P.V.; HANSON; D J.; DRAKE; M. A. Consumer perception of smoke cheddar cheese. Journal of Dairy Science, v.104, n. 2, p. 1560 - 1575, 2021.

DUARTE, Christiane Vaz; VIEIRA, Rafael Porto; GHERARDI, Sandra Regina Marcolino. Fishburguers de tilapia-do-nilo (Oreochromis niloticus) com e sem adição de fumaça líquida. Revista Brasileira de Tecnologia Agroindustrial, Ponta Grossa, v. 11, n. 2, p. 2382-2396, 27 dez. 2017.

FERREIRA NETO, J.; FIGUEIREDO, M. J. de; PEREIRA JUNIOR, E. B.; LIMA FILHO, P.; QUEIROGA, R. A.; LINS, A. C. Queijo tipo coalho defumado com orégano (Origanum vulgare) e erva-doce (Foeniculum vulgare), Revista Principia - Divulgação Científica e Tecnológica do IFPB, n. 36, p. 20-28, João Pessoa, 2017.

FRANCO, R.M.; LEITE, A.M.O. Enumeração e Identificação de Enterococcus spp e Cepas de E. coli Patogênicas em Coxas de Frango e Estudo da Atividade Antimicrobiana das Cepas Isoladas. XV Seminário de Iniciação Científica e Prêmio UFF - Vasconcellos Torres de Ciência e Tecnologia, Nov. 2005.

FURTADO, M. M. Quesos Típicos de Latinoamerica. São Paulo: Danisco A/S, 2005.

GUILLÉN, M.D.; PALENCIA, G.; IBARGOITIA, M.L.; P.SOPELANA. Contamination of cheese by polycyclic aromatic hydrocarbons in traditional smoking. Influence of the position in the smokehouse on the contamination level of smoked cheese. Journal Of Dairy Science, v. 94, n. 4, p. 1679-1690, 2011.

JAFFE, T. R.; WANG, H.; CHAMBERS, E. Determination of a lexicon for the sensory flavor attributes of smoked food products. Journal Of Sensory Studies, v. 32, n. 3, p. 1-9, jun. 2017.

LEDESMA, E.; RENDUELES, M.; DÍAZ, M. Smoked Food. Current Developments In Biotechnology And Bioengineering, Elsevier, p. 201-243, 2017.

LIMA, M. dos S. F. de; SILVA, R. A. da; LIMA FILHO, J. L. de; PORTO, A. L. F.; CAVALCANTI, M. T. H. Queijo de coalho artesanal: fonte alternativa de peptídeos antimicrobianos. Brazilian Journal Of Food Technology, Campinas, v. 20, 2017.

MACHADO, G. de M.; COSTA, R. G. B.; COSTA JÚNIOR, L. C. G.; SOBRAL, D.; 
TAVEIRA, L. B.; SOUZA, B. M. de. Aspectos físico-químicos de queijo de coalho fabricado com o uso de ácido lático. Alimentos e Nutrição Araraquara, v. 22, n. 3, p. 421-428, set. 2011.

MCSWEENEY, P. L. H. Biochemistry of cheese ripening. International Journal Of Dairy Technology, v. 57, n. 2-3, p. 127-144, maio 2004.

MERCK. Microbiological Manual. Berlin, Germany, 407 p., 2002.

MOZANER, L. de Q.; ALMEIDA, A. P. de; SILVA, S. A. da. Hidrocarbonetos policíclicos aromáticos: uma revisão sobre metodologias de análise e níveis de contaminação em produtos cárneos defumados. Revista do Instituto Adolfo Lutz, v. 78, n. 1, p. 1-21, 29 mar. 2019.

NASSU, R. T.; MACEDO, B. A.; LIMA, M. H. P. Queijo de Coalho. Brasília, Df: Embrapa Informação Tecnológica, 2006.

NERO, L. A.; CRUZ, A. G. da; BERSOT, L. dos S. Produção, processamento e fiscalização de leite e derivados. São Paulo: Atheneu Editora, 426 p., 2017.

OLIVEIRA, F. I. P. de; COSTA, M. T. P. da; FRAGA, A. C. A.; OBERG, M. L. B. de M.; VACONCELOS, M. P. de; COSTA, E. da S.; PINTO, S. da C. Ocorrência de Staphylococcus aureus em queijos tipo coalho. Caderno Esp. Ceará: Revista Científica Escola de Saúde Pública do Ceará Paulo Marcelo Martins Rodrigues, v. 13, n. 2, p. 82-93, 19 dez. 2019.

OLIVEIRA, S. P. P.; VALE, O. R. C. do; SILVA, V. R. O.; NOGUEIRA, C. H.; MARTINS, A. D. de O.; MARTINS, J. M.. Queijo minas artesanal do serro: maturação e segurança alimentar. In: Contribuições para a área de alimentos: experiências do mestrado profissional em ciência e tecnologia dos alimentos. Campus Rio Pomba. Rio Pomba: If Sudeste MG, Cap. 4. p. 72-105, 2020

PEDRAL, A. de L.; LEITE, T. S.; SILVA, G. F.; PAGANI, G. D.; PAGANI, A. A. C. Desenvolvimento de um mini defumador de alimentos. VII Simpósio de Engenharia de Produção de Sergipe, São Cristóvão, 2015.

PINTO, M. S.; LEMPK, M. W.; CABRINI, C. C.; SARAIVA, L. K. V.; CANGUSSU, R. R. da C.; CUNHA, A. L. F. S. Características físico-químicas do queijo artesanal produzido na microrregião de montes claros - MG. Revista do Instituto de Laticínios Cândido Tostes, Juiz de Fora, v. 71, n. 1, p. 43-52, mar. 2016.

RIBEIRO, C. de F. A.; PARK, K. J.; HUBINGER, M. D.; RIBEIRO, S. da C. A.; ARAÚJO, E. A. F. Tecnologias para conservação do pescado amazônico. Archives Of Veterinary Science: Inclusão Social, Brasília, v. 12, n. 1, p. 80-94, 13 nov. 2018.

SOUSA, A. Z. B. de; ABRANTES, M. R.; SAKAMOTO, S. M.; SILVA, J. B. A. da; LIMA, P. de O.; LIMA, R. N. de; ROCHA, M. de O. C.; PASSOS, Y. D. B. Aspectos físico-químicos e microbiológicos do queijo tipo coalho comercializado em estados do nordeste do Brasil. Arquivos do Instituto Biológico, v. 81, n. 1, p. 30-35, mar. 2014.

VIDAL, A. M. C.; NETTO, A. S. Obtenção e processamento de leite e derivados. Pirassununga: Faculdade de Zootecnia e Engenharia de Alimentos da Universidade de São 
